\title{
Personality, lifestyle, and risk of cardiovascular disease and cancer: follow-up of population based cohort
}

Til Stürmer, Petra Hasselbach, Manfred Amelang

\begin{abstract}
Objective To study the relation between measures of personality and risk of cardiovascular disease and cancer in a large cohort.

Design Follow-up of population based cohort.

Setting Heidelberg, Germany.

Participants 5114 women and men aged 40-65 in 1992-5.

Main outcome measures Psychological traits assessed by several standardised personality questionnaires in 1992-5, related to cause of death (to 2002-3) or reported incidence of cardiovascular diseases and cancer (validated by treating doctors). Relative risks (and 95\% confidence intervals) for combined morbidity and mortality according to five important personality traits were estimated using multivariable Cox proportional hazards models.

Results During median follow-up of 8.5 years, 257 participants died and 72 were diagnosed with a heart attack, 62 with stroke, and 240 with cancer (morbidity and mortality combined). A high internal locus of control over disease was associated with a decreased risk of myocardial infarction (adjusted relative risk for an increase of $1 \mathrm{SD}=0.75 ; 95 \%$ confidence interval 0.58 to 0.96). An increase of $1 \mathrm{SD}$ in time urgency was associated with a decreased risk of cancer (adjusted relative risk $0.83 ; 0.73$ to 0.95). Other major personality traits-anger control, psychoticism, and symptoms of depression-were not consistently associated with myocardial infarction, stroke, or cancer.

Conclusion Internal locus of control over disease and time urgency seem to be associated with reduced risk for common chronic diseases, probably by affecting unmeasured health related behaviour. The other personality traits assessed had no major impact on cardiovascular disease and cancer.
\end{abstract}

\section{Introduction}

Medicine and psychology have long been separate disciplines. Despite the lack of interdisciplinary studies and cooperation, doctors are aware that psychological traits influence the incidence and the course of chronic diseases.

A recent large multinational case-control study linked permanent stress at work or home during the past year to increased incidence of myocardial infarction. ${ }^{1}$ The size of the effect of psychosocial factors was similar to that seen for abdominal obesity, diabetes, and hypertension. ${ }^{2}$ The proposed pathophysiological links between psychological stress and cardiovascular disease include clustering of "traditional" risk factors, endothelial dysfunction, myocardial ischaemia, plaque rupture, thrombosis, and malignant arrhythmias. ${ }^{34}$
Evidence for a link between psychological factors and cancer is weak. A recent review concluded that "there is not any psychological factor for which an influence on cancer development has been convincingly demonstrated in a series of studies." ${ }^{55}$ A metaanalysis of stressful life events and risk of breast cancer did not support an overall association between such events and breast cancer, except for a modestly increased risk with the death of a spouse. ${ }^{6}$ In a large population based cohort study from Denmark, the incidence of cancer was 18\% higher in mothers 7-18 years after the death of a child. ${ }^{7}$

We hypothesised that personality differences influence the incidence of and mortality from cardiovascular disease and cancer, independent of "traditional" risk factors. We empirically derived five personality scales that measure different independent personality traits ${ }^{8}$ and present results on all five scales without selection according to the strength of association with the disease outcomes.

\section{Methods}

Recruitment and follow-up of the cohort have been described. ${ }^{8}$ Briefly, we identified a representative sample of women and men aged 40-65 from the population registry of Heidelberg, Germany. Between 1992 and 1995, 5114 of these people completed an extensive baseline questionnaire on psychological traits, lifestyle factors, and comorbidity. All participants provided written informed consent to assess their health status 10 years later, including assessment of causes of death.

In 2002, we mailed a follow-up questionnaire to all participants and asked for information about chronic diseases that had been diagnosed since baseline. All participants who did not reply and could not be reached by telephone were followed up through population registries.

\section{Personality variables}

The personality scales used at baseline were selected for several reasons. ${ }^{8}$ Some scales were markers of broad aspects of personality (extraversion, neuroticism, psychoticism). Other scales had been used in research on health outcomes (scales to measure depression, time urgency, hostility, anger out, low sense of coherence, and irritability), some were hypothesised to be relevant (scales to measure optimism, anger in, anger control, social support, exaggerated social control, internal and external locus of control over disease, jealousy), and others were important with respect to response style (scales to measure social desirability).

An additional table is on bmj.com 


\section{Research}

Since many of these personality scales overlap and are highly correlated, we aggregated the information contained in these scales (by using factor analysis) to obtain five broad independent dimensions of personality. ${ }^{8}$ These dimensions are unique to the population from which they were derived. To make it possible to compare our results with reports in the literature, we used the personality scales that were most strongly correlated with these five broad dimensions, rather than the dimensions themselves. Both the derivation of the dimensions and the selection of scales relied solely on cross sectional baseline data (that is, were independent of the disease outcomes), and results are presented for all scales assessed.

\section{Morbidity and mortality}

We validated all diagnoses of myocardial infarction, stroke, and cancer that had occurred since baseline by contacting the treating doctors (with the written informed consent of participants). Mortality follow-up was $99.6 \%$ (22 participants moved to an unknown address or left the country); we assessed the cause of death from death certificates for $98.8 \%$ of participants who had died. Two doctors coded the cause of death according to ICD-10 (international classification of diseases, 10th revision), and inconsistencies were resolved by discussion.

\section{Covariates}

We assessed the risk factors for chronic diseases that might be associated with personality variables at baseline. Besides age and sex, these were body mass index; smoking status; alcohol consumption (amount of beer, wine, and spirits drunk each week); exercise (hours each week); comorbidity (history of myocardial infarction, stroke, cancer, hypertension, hyperlipidaemia, and diabetes); family history of myocardial infarction, stroke, and cancer; and education (years of schooling).

\section{Statistical analyses}

For each participant, we calculated the time to death, diagnosis of disease, or end of follow-up, whichever came first. We used Cox proportional hazards models to assess the association between each personality scale (in thirds or as a continuous variable) and the incidence of myocardial infarction, stroke, or cancer. We excluded participants with the disease at baseline or in whom the incidence of disease could not be assessed because of missing information (247 for myocardial infarction, 274 for stroke, and 256 for cancer).

\section{Results}

Table 1 shows the baseline characteristics of the 4267 participants who replied to the follow-up questionnaire or died during follow-up $(83.4 \%$ of the original cohort). Mean age was 53.4 years; $51.5 \%$ were women. Risk factors for chronic diseases, such as overweight or obesity, smoking, no regular physical exercise, hypertension, hyperlipidaemia, and a family history of myocardial infarction, stroke, or cancer were common.

Table 2 shows the distribution of the five personality scales according to baseline characteristics (actual patient numbers are shown in table A on bmj.com). All scales were divided into low, medium, or high according to the observed distribution (with one third of participants in each category, except for psychoticism, which was split into 22\%, 53\%, and 26\%). Older age was strongly associated with more symptoms of depression and higher anger control. Women were more likely than men to have more symptoms of depression, and men were more likely to have higher anger control, higher time urgency, and higher internal locus of control over disease (the patient's belief that the
Table 1 Baseline characteristics of 4267 participants from the Heidelberg cohort. Values are number (percentage) unless otherwise indicated

\begin{tabular}{|c|c|}
\hline Characteristic & Value \\
\hline Mean (SD) age & $53.4(7.1)$ \\
\hline \multicolumn{2}{|l|}{ Age: } \\
\hline$<50$ years & $1368(32.1)$ \\
\hline 50 to $<60$ & 1945 (45.6) \\
\hline$\geq 60$ & $954(22.4)$ \\
\hline Women & $2197(51.5)$ \\
\hline Mean (SD) body mass index & $25.3(4.0)$ \\
\hline \multicolumn{2}{|l|}{ Body mass index*: } \\
\hline$<25$ & $2183(51.9)$ \\
\hline 25 to $<30$ & $1622(38.6)$ \\
\hline$\geq 30$ & $400(9.5)$ \\
\hline \multicolumn{2}{|l|}{ Smoking status: } \\
\hline Never & $1821(42.9)$ \\
\hline Former & $1524(35.9)$ \\
\hline Current & $896(21.1)$ \\
\hline \multicolumn{2}{|l|}{ Alcohol consumption (g/day)†: } \\
\hline 0 (never/rarely) & $698(16.6)$ \\
\hline 0.5 to $<15$ & $1814(43.1)$ \\
\hline 15 to $<30$ & $940(22.4)$ \\
\hline$\geq 30$ & $753(17.9)$ \\
\hline \multicolumn{2}{|l|}{ Exercise (hours/week)ł: } \\
\hline 0 (none) & $1153(27.2)$ \\
\hline$<1$ & $787(18.6)$ \\
\hline $1-2$ & $1387(32.7)$ \\
\hline$>2$ & $909(21.5)$ \\
\hline \multicolumn{2}{|l|}{ Comorbidity§: } \\
\hline Myocardial infarction & $128(3.2)$ \\
\hline Stroke & $64(1.6)$ \\
\hline Cancer & $242(5.9)$ \\
\hline Hypertension & $1256(31.1)$ \\
\hline Hyperlipidaemia & $1824(44.3)$ \\
\hline Diabetes & $245(6.1)$ \\
\hline \multicolumn{2}{|l|}{ Family historyף: } \\
\hline Myocardial infarction & $1088(25.9)$ \\
\hline Stroke & $966(23.0)$ \\
\hline Cancer & $1685(40.0)$ \\
\hline \multicolumn{2}{|c|}{ Education (total years of schooling) ${ }^{\star *}$ : } \\
\hline$\geq 9$ & $2035(48.2)$ \\
\hline $10-11$ & $920(21.8)$ \\
\hline 12 & $345(8.2)$ \\
\hline$\geq 13$ & $923(21.9)$ \\
\hline
\end{tabular}

*Information missing for 62 participants.

†Calculated from glasses of beer ( 0.5 litre, $\sim 1$ pint), wine $(0.25$ litre, 1 glass), and spirits ( 0.02 litre, 1 shot) regularly drunk each week assuming an alcohol content (\% volume) of 5 (beer), 11 wine, and 40 (shots), and a relative weight of alcohol of 0.8 ; information missing for 62 participants.

flnformation was missing for 31 participants.

§Self reported at baseline; information was missing for 249 participants with myocardial infarction, 231 with stroke, 199 with cancer, 227 with hypertension, 148 with hyperlipidaemia, and 246 with diabetes.

IInformation missing for 61 participants with myocardial infarction, 60 with stroke, and 50 with cancer.

**Information missing for 44 participants.

onset and process of an illness is the result of their behaviour). Higher frequency of exercise was strongly associated with fewer symptoms of depression and higher locus of control. Patients with any comorbidity-especially those with a history of myocardial infarction, stroke, diabetes, or cancer-had more symptoms of depression.

During a median follow-up of 8.5 years, 257 participants died, 72 participants had a heart attack, 62 participants had a stroke, and 240 participants were diagnosed with cancer (morbidity and mortality combined).

Tables 3-5 show the five personality scales (representing the five broad personality dimensions) at baseline as predictors of 
Table 2 Distribution of observed personality scales in 4267 participants from the Heidelberg cohort according to baseline characteristics. Values are percentages (table $\mathrm{A}$ on bmj.com gives the actual numbers)*

\begin{tabular}{|c|c|c|c|c|c|c|c|c|c|c|c|c|c|c|c|}
\hline \multirow[t]{2}{*}{ Variable } & \multicolumn{3}{|c|}{ Symptoms of depression } & \multicolumn{3}{|c|}{ Anger control } & \multicolumn{3}{|c|}{ Time urgency } & \multicolumn{3}{|c|}{$\begin{array}{l}\text { Internal locus of control } \\
\text { over disease }\end{array}$} & \multicolumn{3}{|c|}{ Psychoticism } \\
\hline & Low & Medium & High & Low & Medium & High & Low & Medium & High & Low & Medium & High & Low & Medium & High \\
\hline \multicolumn{16}{|l|}{ Age: } \\
\hline$<50$ & 40 & 32 & 28 & 33 & 36 & 31 & 37 & 32 & 31 & 31 & 34 & 35 & 25 & 51 & 24 \\
\hline 50 to $<60$ & 27 & 36 & 38 & 30 & 37 & 33 & 34 & 31 & 35 & 32 & 33 & 35 & 22 & 53 & 26 \\
\hline$\geq 60$ & 24 & 32 & 44 & 22 & 38 & 40 & 34 & 30 & 36 & 31 & 34 & 35 & 15 & 54 & 31 \\
\hline \multicolumn{16}{|l|}{ Sex: } \\
\hline Female & 23 & 34 & 43 & 35 & 38 & 27 & 40 & 31 & 29 & 36 & 32 & 32 & 20 & 55 & 25 \\
\hline Male & 38 & 34 & 28 & 23 & 36 & 41 & 30 & 31 & 39 & 27 & 35 & 39 & 22 & 50 & 28 \\
\hline \multicolumn{16}{|l|}{ Body mass index: } \\
\hline$<25$ & 33 & 34 & 33 & 31 & 38 & 31 & 38 & 32 & 30 & 33 & 33 & 34 & 20 & 54 & 26 \\
\hline 25 to $<30$ & 29 & 34 & 37 & 27 & 35 & 37 & 31 & 32 & 38 & 30 & 34 & 36 & 22 & 51 & 27 \\
\hline$\geq 30$ & 22 & 33 & 45 & 29 & 38 & 33 & 31 & 29 & 40 & 30 & 33 & 37 & 20 & 51 & 30 \\
\hline \multicolumn{16}{|l|}{ Smoking status: } \\
\hline Never & 28 & 34 & 38 & 29 & 37 & 34 & 36 & 32 & 32 & 32 & 34 & 34 & 20 & 53 & 28 \\
\hline Former & 33 & 35 & 32 & 29 & 37 & 34 & 35 & 30 & 36 & 30 & 35 & 35 & 22 & 53 & 25 \\
\hline Current & 31 & 31 & 38 & 29 & 37 & 34 & 33 & 33 & 33 & 32 & 31 & 37 & 22 & 51 & 27 \\
\hline \multicolumn{16}{|l|}{ Alcohol consumptiont: } \\
\hline 0 (never or rarely) & 27 & 29 & 44 & 30 & 38 & 33 & 39 & 29 & 32 & 33 & 32 & 35 & 21 & 47 & 32 \\
\hline 0.5 to $<15$ & 28 & 35 & 37 & 32 & 37 & 31 & 36 & 32 & 32 & 32 & 34 & 34 & 21 & 55 & 24 \\
\hline 15 to $<30$ & 35 & 36 & 29 & 27 & 37 & 36 & 33 & 32 & 35 & 28 & 35 & 37 & 22 & 54 & 25 \\
\hline$\geq 30$ & 36 & 33 & 31 & 25 & 35 & 39 & 31 & 30 & 39 & 32 & 33 & 36 & 21 & 52 & 27 \\
\hline \multicolumn{16}{|l|}{ Exercise: } \\
\hline 0 (none) & 21 & 33 & 46 & 32 & 36 & 32 & 34 & 31 & 36 & 36 & 31 & 34 & 18 & 51 & 31 \\
\hline$<1$ & 29 & 32 & 39 & 28 & 38 & 34 & 35 & 29 & 36 & 31 & 34 & 34 & 20 & 53 & 26 \\
\hline 1 to 2 & 30 & 35 & 34 & 30 & 37 & 33 & 35 & 33 & 32 & 32 & 35 & 34 & 22 & 54 & 24 \\
\hline$>2$ & 43 & 34 & 23 & 27 & 36 & 37 & 37 & 31 & 32 & 26 & 34 & 40 & 24 & 52 & 24 \\
\hline \multicolumn{16}{|l|}{ Comorbidity:: } \\
\hline Myocardial infarction & 19 & 28 & 53 & 33 & 32 & 35 & 29 & 20 & 52 & 31 & 34 & 34 & 19 & 48 & 34 \\
\hline Stroke & 19 & 22 & 59 & 30 & 36 & 34 & 23 & 31 & 45 & 25 & 30 & 45 & 9 & 39 & 52 \\
\hline Cancer & 19 & 33 & 48 & 30 & 35 & 34 & 39 & 34 & 27 & 33 & 37 & 30 & 25 & 46 & 29 \\
\hline Hypertension & 23 & 35 & 42 & 29 & 36 & 35 & 34 & 29 & 37 & 30 & 35 & 34 & 19 & 54 & 27 \\
\hline Hyperlipidaemia & 24 & 34 & 42 & 29 & 37 & 34 & 32 & 30 & 38 & 29 & 34 & 37 & 21 & 53 & 27 \\
\hline Diabetes & 21 & 31 & 48 & 29 & 33 & 37 & 29 & 31 & 40 & 25 & 31 & 44 & 20 & 47 & 34 \\
\hline \multicolumn{16}{|l|}{ Family history: } \\
\hline Myocardial infarction & 29 & 33 & 38 & 28 & 37 & 35 & 35 & 33 & 32 & 30 & 34 & 35 & 23 & 52 & 25 \\
\hline Stroke & 28 & 33 & 39 & 31 & 36 & 33 & 34 & 31 & 35 & 33 & 32 & 35 & 23 & 52 & 25 \\
\hline Cancer & 29 & 32 & 39 & 31 & 38 & 32 & 35 & 32 & 34 & 34 & 33 & 33 & 20 & 54 & 26 \\
\hline \multicolumn{16}{|l|}{ Education (years): } \\
\hline$\leq 9$ & 23 & 34 & 44 & 30 & 39 & 32 & 33 & 30 & 37 & 30 & 32 & 38 & 21 & 53 & 27 \\
\hline $10-11$ & 31 & 35 & 34 & 32 & 35 & 33 & 38 & 30 & 31 & 30 & 36 & 35 & 23 & 53 & 24 \\
\hline 12 & 40 & 34 & 26 & 25 & 35 & 40 & 36 & 32 & 32 & 29 & 33 & 37 & 20 & 57 & 24 \\
\hline$\geq 13$ & 43 & 34 & 23 & 28 & 36 & 36 & 35 & 34 & 31 & 36 & 35 & 29 & 20 & 51 & 30 \\
\hline
\end{tabular}

*Percentage of participants classified as low, medium, or high in each personality scale according to the observed distribution (one third each for all traits except psychoticism, where the distribution of values was $22 \%, 53 \%$, and $26 \%$ ); 10 values missing for anger control, nine for psychoticism, and nine for symptoms of depression; see table 1 for information on the missing data for the covariates.

†Calculated from glasses of beer ( 0.5 litre, $\sim 1$ pint), wine ( 0.25 litre, 1 glass), and spirits ( 0.02 litre, 1 shot) regularly drunk each week assuming an alcohol content (\% volume) of 5 (beer), 11 wine, and 40 (shots), and a relative weight of alcohol of 0.8 .

$\ddagger$ Self reported at baseline.

incident myocardial infarction, stroke, and cancer during followup. For each personality scale, we performed two separate analyses; one compared the low and the high category to the medium category and one used the $\mathrm{z}$ transformed scores from the original personality scale as a continuous variable, so that the relative risk corresponds to an increase of $1 \mathrm{SD}$ (standard deviation) in the personality scale. The first set of analyses assesses non-monotonic trends and the second assumes a monotonic log-linear trend.

Anger control, time urgency, and symptoms of depression were not associated with the incidence of myocardial infarction (table 3). Participants with a low internal locus of control over disease had an adjusted relative risk of 1.84 (95\% confidence interval 1.01 to 3.32) compared with those with a medium internal locus of control, and participants with a high internal locus of control over disease had a relative risk of 0.77 (0.41 to 1.46$)$. An increase of $1 \mathrm{SD}$ in internal locus of control over disease was associated with a relative risk of 0.75 (0.58 to 0.96$)$. The relative risks of myocardial infarction were 1.59 (0.88 to 2.87 ) and 1.28 (0.71 to 2.30) for participants with low and high psychoticism compared with those with a medium degree of psychoticism. Although this indicates a U-shaped association, an increase of 1 $\mathrm{SD}$ was associated with a relative risk of 1.21 (1.01 to 1.45 ).

None of the personality scales was strongly associated with the incidence of stroke (table 4). Higher values of symptoms of depression, anger control, and time urgency showed a monotonic association with increased risk of incident stroke. In the fully adjusted models, these trends were less pronounced. Higher degrees of psychoticism were associated with a decreased 


\begin{tabular}{|c|c|c|c|c|c|c|}
\hline \multirow{2}{*}{ Personality scale } & \multirow{2}{*}{$\begin{array}{c}\text { Person years }(\mathrm{n}=32 \\
\text { 875) }\end{array}$} & \multirow{2}{*}{$\begin{array}{l}\text { No of events } \\
(n=72)\end{array}$} & \multirow{2}{*}{$\begin{array}{c}\text { Incidence/100 } 000 \text { person years } \\
\text { (219 overall) }\end{array}$} & \multicolumn{3}{|c|}{ Relative risk $(95 \% \mathrm{Cl}) \dagger$} \\
\hline & & & & Unadjusted & Adjusted for age and sex & Fully adjusted $\dagger$ \\
\hline \multicolumn{7}{|c|}{ Symptoms of depression } \\
\hline Low & 10288 & 21 & 204 & 0.81 (0.46 to 1.42$)$ & 0.80 (0.45 to 1.41$)$ & 0.89 (0.48 to 1.64$)$ \\
\hline Medium & 11146 & 28 & 251 & 1.00 & 1.00 & 1.00 \\
\hline High & 11366 & 23 & 202 & 0.80 (0.46 to 1.39$)$ & 0.87 (0.50 to 1.51$)$ & 0.80 (0.44 to 1.43$)$ \\
\hline $1 \mathrm{SD}$ increase & - & - & - & 1.08 (0.86 to 1.35$)$ & 1.17 (0.93 to 1.49$)$ & 1.09 (0.84 to 1.40$)$ \\
\hline \multicolumn{7}{|l|}{ Anger control } \\
\hline Low & 9504 & 16 & 168 & $0.71(0.39$ to 1.31$)$ & 0.88 (0.48 to 1.63$)$ & 0.99 (0.53 to 1.86$)$ \\
\hline Medium & 12198 & 29 & 238 & 1.00 & 1.00 & 1.00 \\
\hline High & 11103 & 27 & 243 & $1.02(0.60$ to 1.72$)$ & 0.81 (0.48 to 1.37$)$ & $0.80(0.45$ to 1.40$)$ \\
\hline $1 \mathrm{SD}$ increase & - & - & - & $1.17(0.92$ to 1.48$)$ & 0.97 (0.77 to 1.23$)$ & 0.91 (0.71 to 1.17$)$ \\
\hline \multicolumn{7}{|l|}{ Time urgency } \\
\hline Low & 11570 & 26 & 228 & $1.30(0.72$ to 2.38$)$ & 1.43 (0.79 to 2.62$)$ & 1.85 (0.94 to 3.62$)$ \\
\hline Medium & 10424 & 18 & 173 & 1.00 & 1.00 & 1.00 \\
\hline High & 10881 & 28 & 257 & 1.49 (0.82 to 2.69$)$ & 1.30 ()0.72 to 2.36 & 1.68 (0.86 to 3.25$)$ \\
\hline $1 \mathrm{SD}$ increase & - & - & - & $1.09(0.87$ to 1.38$)$ & 0.99 (0.78 to 1.26$)$ & 0.99 (0.77 to 1.26$)$ \\
\hline \multicolumn{7}{|c|}{ Internal locus of control over disease } \\
\hline Low & 10218 & 30 & 294 & $1.47(0.85$ to 2.55$)$ & 1.65 (0.95 to 2.86$)$ & 1.84 (1.01 to 3.32$)$ \\
\hline Medium & 11007 & 22 & 200 & 1.00 & 1.00 & 1.00 \\
\hline High & 11650 & 20 & 172 & $0.86(0.47$ to 1.57$)$ & 0.81 (0.44 to 1.48$)$ & 0.77 (0.41 to 1.46$)$ \\
\hline $1 \mathrm{SD}$ increase & - & - & - & 0.87 (0.69 to 1.09) & 0.80 (0.63 to 1.01$)$ & 0.75 (0.58 to 0.96$)$ \\
\hline \multicolumn{7}{|l|}{ Psychoticism } \\
\hline Low & 6980 & 18 & 258 & 1.45 (0.81 to 2.59$)$ & 1.55 (0.87 to 2.79$)$ & 1.59 (0.88 to 2.87) \\
\hline Medium & 17414 & 31 & 178 & 1.00 & 1.00 & 1.00 \\
\hline High & 8411 & 23 & 273 & 1.53 (0.89 to 2.63$)$ & 1.48() 0.86 to 2.54 & 1.28 (0.71 to 2.30$)$ \\
\hline $1 \mathrm{SD}$ increase & - & - & - & 1.22 (1.06 to 1.41$)$ & 1.23 (1.05 to 1.44$)$ & 1.21 (1.01 to 1.45$)$ \\
\hline
\end{tabular}

*128 participants had myocardial infarction at baseline; 247 participants lacked information on incident myocardial infarction during follow-up; 72 incident cases of myocardial infarction (including 31 deaths) occurred.

tIncidence rate ratios and their 95\% confidence intervals from Cox proportional hazards model controlling for all variables in table 1: age (continuous), sex, body mass index ( 3 categories), smoking (never, former, current), alcohol consumption (4 categories), exercise (4 categories), comorbidity (history of stroke, cancer, hypertension, hyperlipidaemia, and diabetes), family history of myocardial infarction, and education (4 categories). Fully adjusted models based on 3700 participants for anger control, 3705 for time urgency, 3705 for internal locus of control over disease, 3698 for psychoticism, and 3697 for symptoms of depression, and 66 events owing to missing information on covariates.

risk of stroke, and this trend was more pronounced after we controlled for confounding.

Table 5 shows that anger control, internal locus of control over disease, psychoticism, and symptoms of depression were not associated with cancer. Time urgency was inversely associated with the risk of cancer; participants with high time urgency had a relative risk for cancer of 0.68 (0.49 to 0.95$)$ compared with those with medium time urgency, and an increase in time urgency of $1 \mathrm{SD}$ was associated with an adjusted relative risk for cancer of 0.83 ( 0.73 to 0.95$)$.

\section{Discussion}

In a large, population based cohort study with a median follow-up of 8.5 years (during which 257 participants died, 72 had a heart attack, 62 had a stroke, and 240 developed cancer) some personality traits were risk factors for morbidity and mortality, independent of lifestyle factors. A low internal locus of control over disease and high and low psychoticism were risk factors for myocardial infarction. A high time urgency was associated with reduced risk of developing cancer. Overall, however, the personality traits had no major impact on the incidence of and mortality from cardiovascular disease and cancer.

\section{Comparison with other studies}

Research on personality variables as risk factors for cardiovascular disease has focused on stress, social support, low sense of coherence, and hardiness. ${ }^{9}$ Findings from the Western Collaborative Group study and the Framingham heart study seemed to establish type A behaviour (the triad of competitive ambition, time urgency, and hostility) as a risk factor for cardiovascular disease. ${ }^{10}{ }^{11}$ But at least one large study (MRFIT; multiple risk factor intervention trial) found no association, and a later analysis of the Western Collaborative Group study found that the association between type A behaviour and all cause mortality is more complex..$^{12}$ Because type A behaviour has now been deconstructed, we analysed anger control (inversely associated with hostility) and time urgency separately. ${ }^{9}$ Neither personality trait was associated with cardiovascular disease, so we cannot confirm the finding of an increased risk of non-fatal myocardial infarction with increasing time urgency seen in a recent case-control study. ${ }^{14}$

A high internal locus of control over disease has consistently been linked with reduced risk of cardiovascular disease. ${ }^{9}$ Our results on myocardial infarction agree with those on control over life circumstances (not disease) seen in a large case-control study. ${ }^{1}$ Residual confounding by healthy behaviours apart from those that we (and others) could control for is a likely explanation for at least part of the reduced risk.

Our finding of increased risk for myocardial infarction with increasing psychoticism needs to be interpreted with caution because of the inconsistency of the results. The analysis based on dividing participants into thirds does not indicate a monotonic association, so that the analysis assuming a monotonic (log linear) trend is probably driven by influential observations at the high end of the highly skewed scale. High values of psychoticism have been associated with less health conscious behaviour in at least one study, but not with myocardial infarction. ${ }^{15}$

Our finding of no association between personality traits and stroke is especially interesting in the light of emerging research on the individual components of composite end points and the greater contribution of stroke than myocardial infarction to overall risk of cardiovascular disease in women. ${ }^{16}$ 


\begin{tabular}{|c|c|c|c|c|c|c|}
\hline \multirow{2}{*}{ Personality scale } & \multirow{2}{*}{$\begin{array}{c}\text { Person years }(\mathrm{n}=33 \\
247)\end{array}$} & \multirow{2}{*}{$\begin{array}{l}\text { No of events } \\
(n=62)\end{array}$} & \multirow{2}{*}{$\begin{array}{c}\text { Incidence } / 100000 \text { person } \\
\text { years (186 overall) }\end{array}$} & \multicolumn{3}{|c|}{ Relative risk $(95 \% \mathrm{Cl}) \dagger$} \\
\hline & & & & Unadjusted & Adjusted for age and sex & Fully adjusted† \\
\hline \multicolumn{7}{|c|}{ Symptoms of depression } \\
\hline Low & 10329 & 12 & 116 & 0.73 (0.35 to 1.51$)$ & 0.79 (0.38 to 1.65$)$ & 0.91 (0.43 to 1.94) \\
\hline Medium & 11322 & 18 & 159 & 1.00 & 1.00 & 1.00 \\
\hline High & 11522 & 32 & 278 & 1.74 (0.98 to 3.10$)$ & 1.68 (0.94 to 3.02$)$ & 1.53 (0.83 to 2.80$)$ \\
\hline $1 \mathrm{SD}$ increase & - & - & - & 1.26 (1.02 to 1.55$)$ & 1.26 (1.01 to 1.58$)$ & 1.13 (0.88 to 1.46$)$ \\
\hline \multicolumn{7}{|l|}{ Anger control } \\
\hline Low & 9665 & 14 & 145 & 0.78 (0.40 to 1.52$)$ & 0.91 (0.47 to 1.76$)$ & 0.87 (0.44 to 1.75$)$ \\
\hline Medium & 12298 & 23 & 187 & 1.00 & 1.00 & 1.00 \\
\hline High & 11213 & 25 & 223 & 1.19 (0.68 to 2.10$)$ & 1.04 (0.59 to 1.84$)$ & 1.15 (0.64 to 2.07$)$ \\
\hline $1 \mathrm{SD}$ increase & - & - & - & 1.14 (0.88 to 1.46$)$ & 1.01 (0.78 to 1.30$)$ & 1.04 (0.80 to 1.36$)$ \\
\hline \multicolumn{7}{|l|}{ Time urgency } \\
\hline Low & 11718 & 16 & 137 & 0.84 (0.42 to 1.66$)$ & 0.84 (0.42 to 1.67$)$ & 0.76 (0.38 to 1.54$)$ \\
\hline Medium & 10404 & 17 & 163 & 1.00 & 1.00 & 1.00 \\
\hline High & 11125 & 29 & 261 & 1.60 (0.88 to 2.91$)$ & 1.45 (0.80 to 2.65$)$ & 1.28 (0.69 to 2.36$)$ \\
\hline $1 \mathrm{SD}$ increase & - & - & - & $1.24(0.97$ to 1.59$)$ & 1.19 (0.93 to 1.53$)$ & 1.15 (0.89 to 1.48$)$ \\
\hline \multicolumn{7}{|c|}{ Internal locus of control over disease } \\
\hline Low & 10328 & 17 & 165 & 0.77 (0.41 to 1.43$)$ & 0.79 (0.42 to 1.47$)$ & 0.79 (0.42 to 1.49$)$ \\
\hline Medium & 11126 & 24 & 216 & 1.00 & 1.00 & 1.00 \\
\hline High & 11794 & 21 & 178 & 0.82 (0.46 to 1.48$)$ & 0.79 (0.44 to 1.42$)$ & 0.65 (0.35 to 1.21$)$ \\
\hline $1 \mathrm{SD}$ increase & - & - & - & $1.14(0.89$ to 1.47$)$ & 1.11 (0.86 to 1.43$)$ & $1.01(0.78$ to 1.30$)$ \\
\hline \multicolumn{7}{|l|}{ Psychoticism } \\
\hline Low & 7111 & 14 & 197 & 1.01 (0.54 to 1.89$)$ & 1.18 (0.63 to 2.21$)$ & 1.20 (0.64 to 2.27$)$ \\
\hline Medium & 17543 & 34 & 194 & 1.00 & 1.00 & 1.00 \\
\hline High & 8525 & 14 & 164 & 0.85 (0.46 to 1.58$)$ & 0.83 (0.45 to 1.55$)$ & $0.70(0.36$ to 1.36$)$ \\
\hline $1 \mathrm{SD}$ increase & - & - & - & 0.94 (0.72 to 1.25$)$ & 0.89 (0.67 to 1.20$)$ & 0.81 (0.58 to 1.12$)$ \\
\hline
\end{tabular}

*64 participants had stroke at baseline; 274 participants lacked information on incident stroke during follow-up; 62 incident cases of stroke (no deaths) occurred.

fIncidence rate ratios and their $95 \%$ confidence intervals from Cox proportional hazards model controlling for all variables in table 1: age (continuous), sex, body mass index (3 categories),

smoking status (never, former, current), alcohol consumption (4 categories), exercise (4 categories), comorbidity (history of stroke, cancer, hypertension, hyperlipidaemia, and diabetes), family

history of stroke, and education (4 categories). Fully adjusted models based on 3741 participants for anger control, 3746 for time urgency, 3746 for internal locus of control over disease, 3739

for psychoticism, and 3738 for symptoms of depression, and 59 events owing to missing information on covariates.

A recent review of the association between psychological factors and cancer concluded that life events (other than loss of a spouse or child), negative emotional states, fighting spirit, stoic acceptance or fatalism, active coping, personality factors, and locus of control have little influence on whether people develop cancer or not. ${ }^{5}$ We found that a high time urgency was associated with a lower risk of cancer, but the strength of the association was moderate, and risk was not increased in the category of low time urgency. High time urgency has been associated with a decreased risk for all cause mortality in women after myocardial infarction but not with a decreased risk for any type of cancer. ${ }^{17}$ High time urgency might be associated with delayed diagnosis and thus lower incidence of cancer. Secondary analyses restricted to 83 deaths caused by cancer showed similar results, but with an adjusted hazards ratio of 0.58 (0.32 to 1.05$)$ for high versus medium time urgency and of 0.80 (0.64 to 1.00) for an increase of 1 SD. By looking at cancer overall, we may have missed associations with individual types of cancer. A meta-analysis found a modest increase in risk of breast cancer after the death of a spouse but did not support an overall association between stressful life events and risk of breast cancer. ${ }^{6}$ A previous review reached similar conclusions. ${ }^{18}$

\section{Limitations}

We lack information on important risk factors for cardiovascular disease and cancer, including blood lipids, markers of subclinical systemic inflammation, diet, and use of drugs (for example, low dose aspirin, statins) during follow-up. Whereas an association between personality variables and biological markers is unlikely, personality variables could be associated with long term use of preventive drugs, screening practices, and reporting of symptoms. ${ }^{19}$ It might be better not to control for such covariates that are consequences rather than confounders.
Despite the population based recruitment, participants probably do not represent the whole range of personalities in the population. We might have missed associations between extreme patterns of these traits and disease.

\section{Implications}

Psychological traits such as the personality variables considered in our analysis are probably stable over time and are likely to have a genetic component. ${ }^{20}{ }^{21}$ The more these traits are predetermined, the more they should be seen as part of a risk prediction rather than be used for "victim blaming". Life events seem to influence the stability of these traits, and some events (such as becoming unemployed) might be avoidable at the level of the individual or society. ${ }^{20}{ }^{22}$ We assessed personality variables at baseline with an extensive list of validated scales under standardised conditions, and we used factor analysis to find five personality scales as indicators for five independent personality dimensions without information on outcomes. ${ }^{8}$ An analysis that adjusted for multiple comparisons found no statistically significant association. We did not adjust the results for multiple comparisons because it is unlikely that all associations between personality traits and disease are random, because we chose all scales without knowledge of the outcomes, and because we present all the associations that we evaluated. ${ }^{23}$

Mortality and morbidity follow-up were almost complete and the incidence of the chronic diseases was validated, so the estimates of relative risks should be valid, even if we missed some events.

We adjusted our analyses for various lifestyle factors at baseline (smoking, alcohol consumption, body mass index, physical exercise, and education). Since the personality variables and these lifestyle factors were assessed at the same time, we cannot tell how personality variables influenced these lifestyle factors. 


\begin{tabular}{|c|c|c|c|c|c|c|c|}
\hline \multirow{2}{*}{ Personality scale } & \multirow{2}{*}{$\begin{array}{c}\text { Person years }(\mathrm{n}=31 \\
257)\end{array}$} & \multirow{2}{*}{$\begin{array}{c}\text { No of events } \\
(\mathrm{n}=240)\end{array}$} & \multirow{2}{*}{$\begin{array}{c}\text { Incidence/100 } 000 \text { person } \\
\text { years (768 overall) }\end{array}$} & \multicolumn{4}{|c|}{ Relative risk $(95 \% \mathrm{Cl}) \dagger$} \\
\hline & & & & & Unadjusted & Adjusted for age and sex & Fully adjusted $\dagger$ \\
\hline \multicolumn{8}{|c|}{ Symptoms of depression } \\
\hline Low & 9878 & 79 & 800 & 1.26 & (0.91 to 1.75$)$ & 1.37 (0.99 to 1.91$)$ & 1.35 (0.96 to 1.88$)$ \\
\hline Medium & 10493 & 66 & 629 & & 1.00 & 1.00 & 1.00 \\
\hline High & 10810 & 95 & 879 & 1.39 & (1.02 to 1.91$)$ & 1.31 (0.95 to 1.79$)$ & $1.18(0.85$ to 1.63$)$ \\
\hline $1 \mathrm{SD}$ increase & - & - & - & 1.09 & $(0.97$ to 1.23$)$ & 1.06 (0.93 to 1.20$)$ & $1.00(0.87$ to 1.15$)$ \\
\hline \multicolumn{8}{|l|}{ Anger control } \\
\hline Low & 9106 & 56 & 615 & 0.80 & (0.57 to 1.12$)$ & $0.86(0.62$ to 1.20$)$ & 0.87 (0.62 to 1.23$)$ \\
\hline Medium & 11615 & 90 & 775 & & 1.00 & 1.00 & 1.00 \\
\hline High & 10479 & 93 & 887 & 1.14 & $(0.85$ to 1.53$)$ & 1.09 (0.81 to 1.46$)$ & $1.14(0.84$ to 1.54$)$ \\
\hline $1 \mathrm{SD}$ increase & - & - & - & 1.10 & $(0.97$ to 1.25$)$ & 1.04 (0.91 to 1.19$)$ & $1.06(0.93$ to 1.22$)$ \\
\hline \multicolumn{8}{|l|}{ Time urgency } \\
\hline Low & 10856 & 93 & 857 & 1.04 & $(0.77$ to 1.40$)$ & 1.06 (0.78 to 1.42$)$ & $1.08(0.80$ to 1.47$)$ \\
\hline Medium & 9746 & 81 & 831 & & 1.00 & 1.00 & 1.00 \\
\hline High & 10654 & 66 & 619 & 0.74 & $(0.54$ to 1.03$)$ & 0.71 (0.51 to 0.98$)$ & 0.68 (0.49 to 0.95$)$ \\
\hline $1 \mathrm{SD}$ increase & - & - & - & 0.87 & $(0.76$ to 0.99$)$ & 0.85 (0.74 to 0.96$)$ & 0.83 (0.73 to 0.95$)$ \\
\hline \multicolumn{8}{|c|}{ Internal locus of control over disease } \\
\hline Low & 9716 & 85 & 875 & 1.25 & (0.92 to 1.71$)$ & 1.25 (0.92 to 1.72$)$ & 1.20 (0.87 to 1.66$)$ \\
\hline Medium & 10391 & 73 & 703 & & 1.00 & 1.00 & 1.00 \\
\hline High & 11149 & 82 & 735 & 1.04 & (0.76 to 1.43 ) & 1.01 (0.74 to 1.38 ) & 1.00 (0.72 to 1.38$)$ \\
\hline $1 \mathrm{SD}$ increase & - & - & - & 0.99 & (0.87 to 1.13$)$ & 0.98 (0.86 to 1.11$)$ & 0.98 (0.86 to 1.12$)$ \\
\hline \multicolumn{8}{|l|}{ Psychoticism } \\
\hline Low & 6577 & 55 & 836 & 1.17 & (0.85 to 1.62$)$ & $1.29(0.93$ to 1.77$)$ & 1.34 (0.97 to 1.85$)$ \\
\hline Medium & 16614 & 118 & 710 & & 1.00 & 1.00 & 1.00 \\
\hline High & 7996 & 67 & 838 & 1.18 & (0.87 to 1.59$)$ & $1.16(0.86$ to 1.57$)$ & 1.16 (0.85 to 1.58$)$ \\
\hline $1 \mathrm{SD}$ increase & - & - & - & 1.06 & (0.95 to 1.19) & $1.04(0.92$ to 1.16$)$ & 1.01 (0.89 to 1.14$)$ \\
\hline
\end{tabular}

*242 participants had cancer at baseline; 256 participants lacked information on incident cancer during follow-up; 240 incident cases of myocardial infarction (including 83 deaths) occurred. †Incidence rate ratios and their $95 \%$ confidence intervals from Cox proportional hazards model controlling for all variables in table 1: age (continuous), sex, body mass index ( 3 categories), smoking status (never, former, current), alcohol consumption (4 categories), exercise (4 categories), comorbidity (history of stroke, cancer, hypertension, hyperlipidaemia, and diabetes), family history of cancer, and education (4 categories). Fully adjusted models based on 3587 participants for anger control, 3591 for time urgency, 3591 for internal locus of control over disease, 3584 for psychoticism, and 3583 for symptoms of depression, and 230 events owing to missing information on covariates.

Psychological traits probably influence the risk of disease only after long latency periods, but they might have more immediate effects through variables such as lifestyle factors (smoking, alcohol consumption, and weight). ${ }^{24}$ We therefore adjusted for age and sex only as well as for these two factors plus lifestyle factors. Repeated measures and more sophisticated models are needed to determine the causal effect of personality differences on the risk of disease.

Contributors: MA and TS designed the study and obtained funding; $\mathrm{PH}$ collected the data; TS and PH analysed the data; TS drafted the paper; TS, $\mathrm{PH}$, and MA helped to write the paper. MA is guarantor.

\section{What is already known on this topic}

Evidence of an effect of personality on disease is best for stress and cardiovascular disease, but little evidence exists for cancer

\section{What this study adds}

Overall, the personality traits assessed had no major impact on incidence of and mortality from cardiovascular disease and cancer

Higher internal locus of control over disease (a patient's belief that the onset and progress of disease is a result of their behaviour) may be associated with a reduced risk of myocardial infarction but not of stroke or cancer

Higher time urgency may be associated with a reduced risk of cancer but not of cardiovascular disease (myocardial infarction and stroke)
Funding: German Research Foundation (research grant AM 37/19-1).

Competing interests: None declared.

Ethical approval: Ethics committee-I of the medical faculty of Heidelberg, Ruprecht-Karls University of Heidelberg, Germany.

1 Rosengren A, Hawken S, Ounpuu S, Sliwa K, Zubaid M, Almahmeed WA, et al. Association of psychosocial risk factors with risk of acute myocardial infarction in 11119 cases and 13648 controls from 52 countries (the INTERHEART study): case-control study. Lancet 2004;364:953-62.

2 Yusuf S, Hawken S, Ounpuu S, Dans T, Avezum A, Lanas F, et al. Effect of potentially modifiable risk factors associated with myocardial infarction in 52 countries (the INTERHEART study): case-control study. Lancet 2004;364:937-52.

3 Merz CNB, Dwyer J, Nordstrom CK, Walton KG, Salerno JW, Schneider RH Psychological stress and cardiovascular disease: pathophysiological links. Behav Med 2002;27:141-7.

4 Black PH, Garbutt LD. Stress, inflammation and cardiovascular disease. J Psychosom Res 2002;52:1-12.

5 Garssen B. Psychological factors and cancer development: evidence after 30 years of research. Clin Psychol Rev 2004;24:315-38

6 Duijts SF, Zeegers MP, Borne BV. The association between stressful life events and breast cancer risk: a meta-analysis. Int J Cancer 2003;107:1023-9.

7 Johansen C, Hansen D, Olsen J. Cancer incidence in parents who lost a child. Cancer 2002;95:2237-42.

8 Amelang M, Hasselbach P, Stürmer T. Personality, cardiovascular disease, and cancer. Z Gesundheitspsychol 2004;12:102-15.

9 Sutton S, Baum A, Johnston M, eds. The Sage handbook of health psychology. London: Sage, 2004.

10 Ragland DR, Brand RJ. Type A behaviour and mortality from coronary heart disease. N Engl J Med 1988;318:65-9.

11 Haynes SG, Feinleib M, Kannel WB. The relationship of psychosocial factors to coronary heart disease in the Framingham study. III. Eight-year incidence of coronary heart disease. Am J Epidemiol 1980;111:37-58.

12 Shekelle RB, Hulley SB, Neaton JD, Billings JH, Borhani NO, Gerace TA, et al. The MRFIT behaviour pattern study. II. Type A behaviour and incidence of coronary heart disease. Am J Epidemiol 1985;122:559-70.

13 Carmelli D, Swan GE. The relationship of type A behaviour and its components to allcause mortality in an elderly subgroup of men from the western collaborative group study. J Psychosom Res 1996;40:475-83.

14 Cole SR, Kawachi I, Liu S, Gaziano JM, Manson JE, Buring JE, Hennekens CH. Time urgency and risk of non-fatal myocardial infarction. Int J Epidemiol 2001:30:363-9.

15 Brayne C, Do KA, Green L, Green AC. Is health protective behaviour in adolescents related to personality? A study of sun protective behaviour and the Eysenck personalrelated to personality? A study of sun protective behaviour and the Eysenck perso
ity questionnaire (junior version) in Queensland. Pers Individ Dif 1998;25:889-95.

ity questionnaire (junior version) in Queensland. Pers Individ Dif 1998;25:889-95.
6 Glynn RJ, Rosner B. Methods to evaluate risks for composite end points and their individual components. J Clin Epidemiol 2004;57:113-22. 
17 Powell LH, Shaker LA, Jones BA, Vaccarino LV, Thoresen CE, Pattillio JR. Psychosocial predictors of mortality in 83 women with premature acute myocardial infarction. Psy-

18 Butow PN, Hiller JE, Price MA, Thackway SV, Kricker A, Tennant CC. Epidemiological evidence for a relationship between life events, coping style, and personality factors in the development of breast cancer. J Psychosom Res 2000;49:169-81.

19 Macleod J, Smith GD, Heslop P, Metcalfe C, Carroll D, Hart C. Psychological stress and cardiovascular disease: empirical demonstration of bias in a prospective observational study of Scottish men. BMJ 2002;324:1247-51.

20 Vaidya JG, Gray EK, Haig J, Watson D. On the temporal stability of personality: evidence for differential stability and the role of life experiences. I Pers Soc Psychol 2002;83:1469-84.

21 Borkenau P, Riemann R, Angleitner A, Spinath FM. Genetic and environmental influences on observed personality: evidence from the German observational study of adul twins.J Pers Soc Psychol 2001;80:655-68.

22 Vahtera J, Kivimaki M, Pentti J, Linna A, Virtanen M, Virtanen P, et al. Organisationa downsizing, sickness absence, and mortality: 10-town prospective cohort study. $B M$ J 2004;328:555.
23 Rothman KJ. No adjustments are needed for multiple comparisons. Epidemiology $1990 ; 1: 43-6$.

24 Weitkunat R, Wildner M. Exploratory causal modeling in epidemiology: are all factors created equal? J Clin Epidemiol 2002;55:436-44.

(Accepted 13 April 2006)

doi $10.1136 /$ bmj.38833.479560.80

Divisions of Pharmacoepidemiology and Pharmacoeconomics, and Preventive Medicine, Brigham and Women's Hospital, Harvard Medical School, Boston, MA 02120, USA

Til Stürmer visiting associate professor of medicine

Department of Psychology, University of Heidelberg, Germany

Petra Hasselbach research fellow

Manfred Amelang professor of psychology

Correspondence to: T Stürmer til.sturmer@post.harvard.edu 